\title{
Design of a New Type of Charging Station for Solar Electric Vehicle Huaizhong Chen
}

\author{
Zhejiang Industry Polytechnic College, Shaoxing, China \\ Chz702@163.com
}

Keywords: Integrated photovoltaic; Charging station; New energy vehicle ; Solar electric vehicle

\begin{abstract}
With the introduction of new energy electric vehicle subsidy policy, the construction of automatic charging station has become a major obstacle to the rapid development of China's new energy vehicles. In this paper, a new type of solar charging station is designed according to the requirement of the photovoltaic charging characteristic. The output power of solar array as the sun radiation intensity, temperature and load changes, make solar array work in the most power output state is solar array and DC bus interface 's main function. The interface between the DC bus and Solar array through most high power control method to realize the solar array of maximum power `s tracking and control. The solar photovoltaic power generation is applied to the electric bicycle load through the DC bus, and the voltage regulation of the DC bus bar through the energy storage device has good effect.
\end{abstract}

\section{Introduction}

In the face of the environmental problem caused by the traditional fuel vehicle exhaust emissions caused by air pollution and its oil resources to huge consumption, electric vehicle because of its good characteristic of energy saving and environmental protection, quickly became today's vehicle development trend and the trend. Electric vehicles are different from the conventional car is the most prominent feature is to rely on power driven, electric power can fill in time or not, directly related to the electric car can continue to use. Prior to the existence of the electric vehicle type, whether it is a pure electric vehicles or hybrid electric vehicles, are inevitably required to allow the support of the power station. Before most of the electric vehicle allows power plants are using conventional electricity as a source of electrical power, which requires the strong support of the urban distribution network, so there is a restricted area is large; and the solar energy as renewable energy, is to protect the earth's ecological environment for human survival clean energy source, everywhere has the characteristics of using solar power as the power source of the electric vehicle allows power station will become a kind of green and environmental protection for power[1-2].

For use of photovoltaic power generation and storage system, in combination with conventional grid electricity and network force method, to establish a safe and reliable, no noise, no pollution of solar grid storage type electric vehicle status of the power system, in order to achieve stable for the electric vehicle charging and achieve energy-saving emission reduction.

\section{Charging Mode}

To introduce charging stations for electric vehicle charging mode are generally classified into three types: slow charge mode: using vehicle mounted allows electrical charge, the general status of the electric asked in 4-8 $\mathrm{h}$, through the communication status of the electric pile completion status of the electric for household cars allow electricity. Fast charge mode:: in the status of the power station to achieve medium speed, high speed high power charging, the general status of the electric Qh 20 min. Through DC allow electric pile completion status of the power for electric buses, city buses allow electricity to. The system is called a direct current power system. Mainly composed of DC power supply system and DC power supply. Replacement of the battery is one of the most rapid and convenient mode. The battery is not included in the price of cars, replace the battery does not need to pay, which is loved by the people [3]. 
At present, the power supply of the conventional power supply system is mainly composed of AC power distribution, rectifier module, DC power distribution, monitoring module and the permissible electric pile. In the electric car of the future status of the power plant construction, may appear three allows electric mode also appeared in the situation of the status of the power plant, which will provide for different periods of time allows the user provides more choices, the user can select the allow electric mode according to their own needs.

\section{Solar Charging Station Systems}

System Working Principle. Solar grid connected energy storage system can be integrated photovoltaic module, DC power distribution equipment, storage battery, charging station intelligent control system, charging interface and power grid interface, etc., the specific system structure as shown in Fig. 1[4-5].

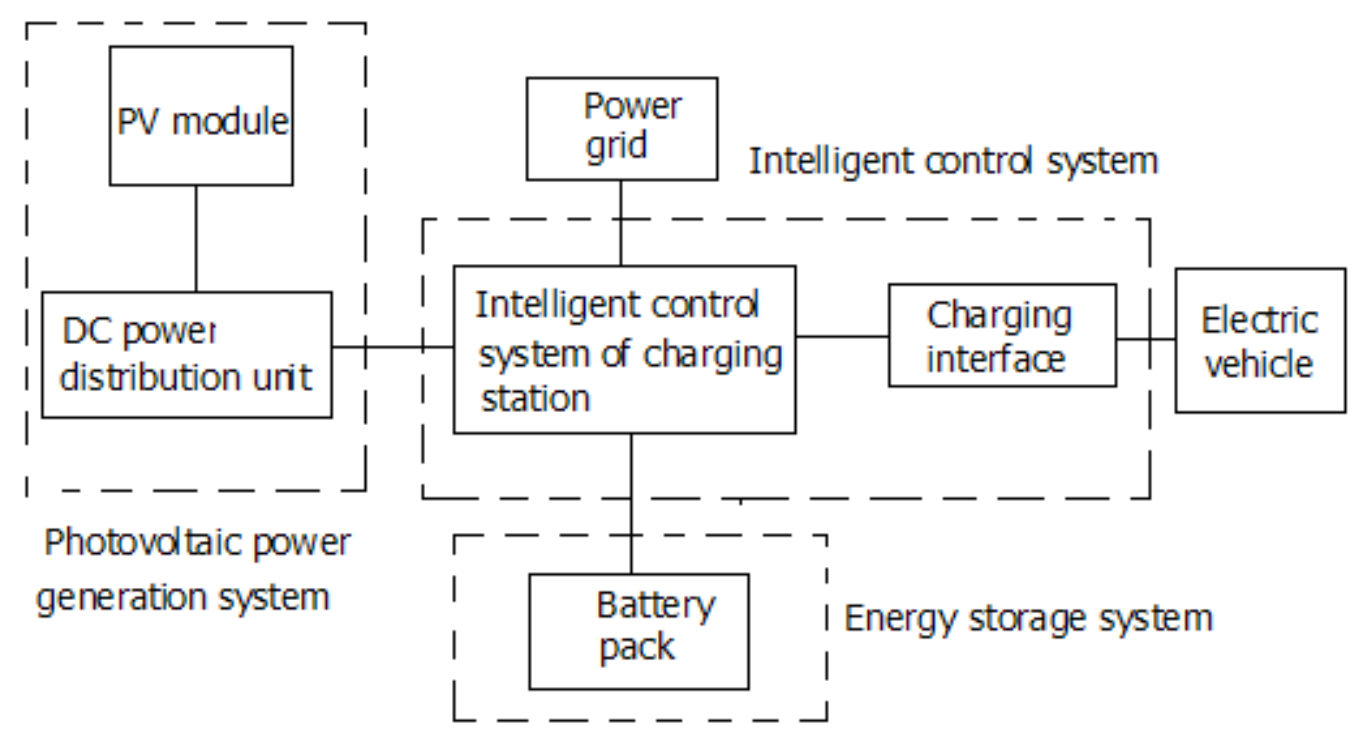

Figure 1. Structure of solar charging system

With plenty of sunshine during the day and PV systems send DC after DC distribution unit confluence, by charging station, intelligent control system to control the charging and discharging control module to the battery storage, again through the bi-directional inverter module connected to the charging interface for electric vehicle power supply and excess capacity by grid connected into the power grid. At night or on cloudy weather when the storage is inadequate, grid through the intelligent control system to supply power to the electric car, also through the intelligent control system in the bi-directional inverter module for storage battery power supply storage, so as to effectively guarantee the charging station continuous and stable operation. System features are as follows:

Universal. The solar charging station system of intelligent control system with automatic analysis ability to identify various types of battery system and various voltage levels, and all kinds of pure electric vehicle power battery system to achieve charging characteristics matching, for different battery charging, full foot in public places and all kinds of electric vehicle charging interface, a charging criterion and interface protocol standard general use.

Intelligent. Intelligent reflected in the system for intelligent power distribution, charging and discharging intelligent and intelligent detection and measurement. Intelligent discharge can realize nondestructive charging and discharging of the energy storage battery through optimized intelligent charging and discharging technology, monitoring battery state of charge and discharge, to avoid too charge and discharge phenomenon, to accomplish the battery fault automatic diagnosis and maintenance, so as to extend the battery life and energy saving[6]. 
Convenience. Users can directly through the charging station, intelligent control system of liquid crystal touch screen for charging type selection, query volume charging, charging the cost of query, network information query, print invoices, both convenient and humanized.

\section{Constant Method}

MPPT Control Method. The output power of the PV array with the external light intensity and environment temperature changes and changes, but a moment, only an output power at the maximum value, in the maximum output power of the point of maximum power point. Therefore, the maximum power point tracking is based on the change of the external environment, and constantly adjust the working point of the photovoltaic array, so that it works at the maximum power point. The goal of maximum power point tracking is to allow the solar cell is the maximum power output of the battery in real time, so that it has the maximum efficiency [7-8].

CVT Control Method. The basic thought of constant voltage tracking method is to control the output voltage of photovoltaic cell at a fixed place; the output voltages of photovoltaic arrays are all distributed around this voltage. At this time, the photovoltaic array approximately works at the maximum power point. The constant Voltage tracking output characteristics is shown as Fig. 2.

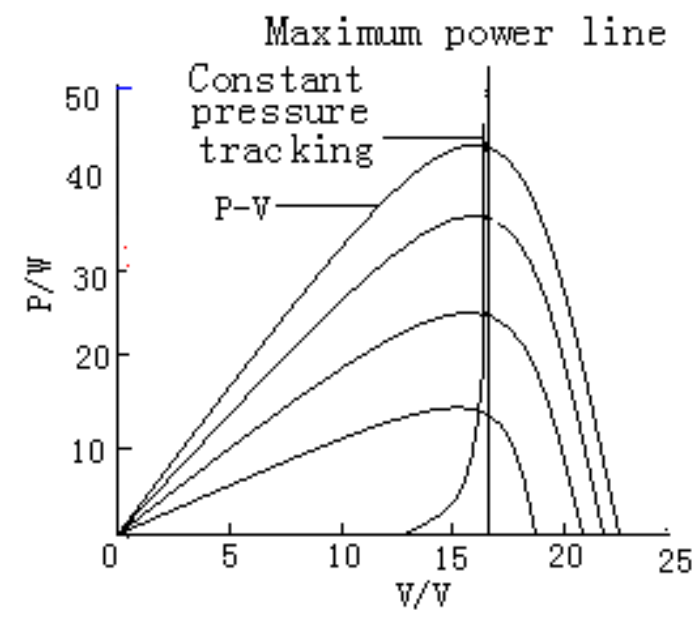

Figure 2. Constant Voltage Tracking output characteristics

It can be seen from the figure, when the temperature is constant, under different light intensity of solar panels maximum power point almost in the same vertical line on both sides of the adjacent, which may the maximum power line approximately as $\mathrm{V}$ voltage constant of a root vertical line, the photovoltaic panels to a fixed voltage. Constant pressure tracking method is an approximate maximum power tracking method.

The design idea and structure of constant voltage method is simple, easy to control, easy to implement, high reliability and stability [9].

INC Control Method. Incremental conductance method is a kind of the most commonly used maximum power point tracking (MPPT) control algorithm, its principle is through the comparison of the relationship between the PV array output voltage and current, that is, PV array conductance increment and instantaneous conductance to change the control mode of the system. The incremental conductance method is simple and accurate control, fast response speed, especially suitable for the light intensity changing environment, but the INC on the hardware requirements, especially for mining. Kind of sensor with high precision of the whole system, so the incremental conductance method to control the cost is relatively high [10-11]. 


\section{Conclusions}

Comply with the rise of new energy vehicles, the solar energy grid storage energy type charging station system in full consideration of the light environment, such as a variety of environmental factors based on the advanced design concepts, a collection of new energy in the field of photovoltaic power generation, energy storage, grid, charging etc., many new technologies, fully embodies the its scientific rationality, economy, security and other characteristics, for the electric vehicle charging station construction provides an innovative integration solutions.

\section{Acknowledgements}

This work is supported by scientific research funded project of Science Technology Department of Zhejiang Province (2015C31128).

\section{References}

[1] Y Hang: Application Research on a Stand-alone PV System with Ultracapaticor Battery Hybrid Energy Storage. Master degree thesis of Chongqing University, Vol.43 (2011), No.3, p.567-575.

[2] X Feng, Z Yeand 1 Xing: Impedance specification and impedance improvement for DC distributed power system. PESC 30th Annual IEEE, Vol.23 (2013), No.1, p.889-894.

[3] Emadi A, Ehsani M: Negative impedance stabilizing controls for PWM DC-DC converters using feedback linearization techniques. IECEC 35th Intersociety, Vol.23 (2000) No.1p613-620.

[4] Cegnar E J, Hess H L and Johnson B K: A purely ultracapacitor energy storage system hybrid electric vehicles utilizing a based DC-DC boost converter. Nineteenth Annual IEEE Applied Power Electronics Conference and Exposition, Vol 23(2004), No.1, p 1160-1164.

[5] Dixon J W, Oriuzar M E: Ultra capacitors DC-DC converters in regenerative braking system. IEEE Aerospace and Electronic Systems Magazine, Vol.17 (2002), No.8p.16-21.

[6] Mellor P H, Schofield N: Howe D: Flywheel and super capacitor peak power buffer technologies .IEE Seminar 11 on Electric, Hybrid and Fuel Cell Vehicles. Sheffield Univ England, Vol.17 (2012) No.8, p1-5.

[7] Junseok Song:Development of a Markov-Chain-Based Energy Storage Model for Power Supply Availability Assessment of Photovoltaic Generation Plants. IEEE Sustainable Energy, Vol.17 (2013) No.2p.491-499.

[8] Ahmed E M, Shoyama M: Scaling factor design issues in variable step size incremental resistance

[9] MPPT in PV systems. The 2011 IEEE Ninth International Conference on Power Electronics and

[10]Drive Systems.Vol.1 (2011) No.2p.891-894.

[11] Sun K, Zhang L, Xing Y: A distributed control strategy based on DC bus signaling for modular

[12] Photovoltaic generation systems with battery energy storage. IEEE Transactions on Power Electronics, Vol.26 (2011) No.10p.3032-3045.

[13]Si Jiang: Quasi-Z-Source inverter with energy storage for Photovoltaic power generation systems. The 2011 Twenty-Sixth Annual IEEE on Applied Power Electronics Conference and Exposition, 2011:401-406.

[14] Vulturescu, S.Butterbach: Ageing study of a super capacitor-battery storage system. Electrical Machines Conference, Vol.21 (2010), No.1, p.147-152. 